\title{
Analysis of environmental impact caused from diesel passenger cars in Tirana district by using PEMS method: cases of Lancia and Citroen
}

\author{
Lorenc Malka $^{1}$, Klodian Dhoska ${ }^{2}$ \\ ${ }^{1}$ Department of Energy, Polytechnic University of Tirana, Tirana, Albania \\ ${ }^{2}$ Department of Mechatronics, Tallinn University of Technology, Tallinn, Estonia
}

Received: 09 March 2016

Accepted: 17 May 2016

*Correspondence:

Lorenc Malka

E-mail: 1malka@fim.edu.al

Copyright: $\odot$ the author(s), publisher and licensee Medip Academy. This is an open-access article distributed under the terms of the Creative Commons Attribution Non-Commercial License, which permits unrestricted non-commercial use, distribution, and reproduction in any medium, provided the original work is properly cited.

\begin{abstract}
Background: Road transportation is the major fuel consumer and greenhouse gas emitter in the Tirana district. Emission and fuel consumption estimation models play a key role in the evaluation of the environmental emission impact caused from diesel passenger cars. Tirana as a metropolitan city of Albania is facing a serious problem that continues to be critical for the high uncontrolled level of pollution caused from this sector. Hydrocarbons (HC), Carbon dioxide $\left(\mathrm{CO}_{2}\right)$ and Nitrogen oxides (NOx) are important pollutants caused by internal combustion diesel engine which simultaneously influence in ambient air quality. Analysis of the environmental impact in Tirana district for measuring $\mathrm{HC}$, $\mathrm{NOx}$ and $\mathrm{CO}_{2}$ were briefly described in this paper.

Methods: The emission level of the diesel passenger cars was measured by using E8500 gas analyser device in Tirana District. Emissions were measured over urban zone and extra urbane highway Tirana-Durrës, in total more than 50 hours of operation and 500 kilometers driven.

Results: The values outside of the optimal speeds simultaneously increase the $\mathrm{CO}_{2}$ by increasing the fuel consumption and vice versa. The $\mathrm{HC}$ and NOx content is increased by increasing the speed regime.

Conclusions: This study can be concluded that various factors influence the emission level of $\mathrm{HC}, \mathrm{NOx}, \mathrm{CO}_{2}$ and the use of average speed is the explanatory variable which is insufficient for estimating cars fuel consumption and especially $\mathrm{HC}$ and NOx emissions.
\end{abstract}

Keywords: Gas emitter, Pollutants, Hydrocarbons, Nitrogen oxide, Carbon dioxide

\section{INTRODUCTION}

Over the last decade, air pollution in the Republic of Albania is in a crucial moment and an actual problem that effect on human health. ${ }^{1}$ Many of the problems has been noticed in the industrial cities and urban zones where the number of industries and road transport has grown rapidly. The level of environmental impact is increased rapidly and affecting simultaneously in the Albanian quality life. Furthermore, vehicle emission estimation models play an important role in the evaluation of the vehicle environmental emission impact that come from road transport sector in Albania

Currently, the transportation sector is one of the main sources of pollution in the Republic of Albania. Tirana, as a metropolitan city of Albania, has counted the largest vehicle passenger cars with $35 \%$, where $71 \%$ of them were diesel internal combustion engines. ${ }^{3}$ This park of vehicles is the main source of environmental pollution in Tirana district which increasing the number of diseases almost in lung respiratory and heart problems in accordance to Albanian Health Institute. ${ }^{1}$ 
Hydrocarbons (HC), Nitrogen oxide (NOx) and Carbon Dioxide $\left(\mathrm{CO}_{2}\right)$ are the main common pollutants of the diesel engine which play a key role in tropospheric chemistry and influenced directly in the ambient air pollution. Based on it, many diseases in Tirana district were growing during last decade and are related to these common pollutants as can be seen in the Figure 1:

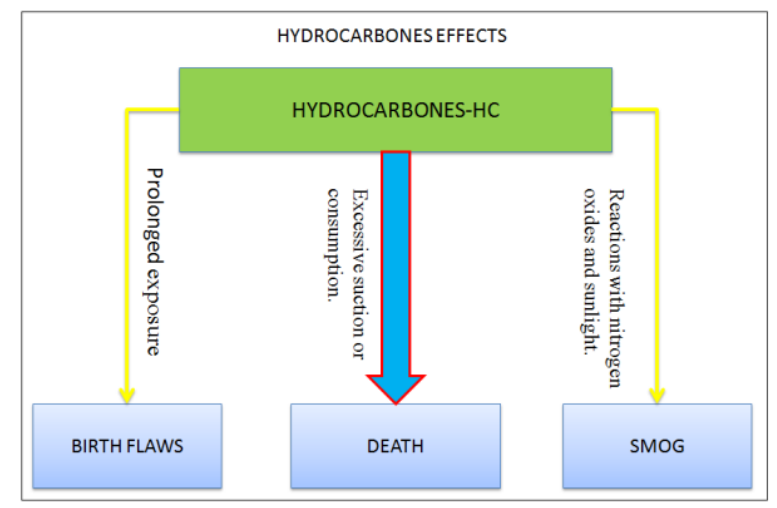

Figure 1: Impact of HC on human and environment.

$\mathrm{CO}_{2}$ is a product of complete combustion of the fuel. $\mathrm{CO}_{2}$ does not affect directly to the human health but it is a greenhouse gas and is one of the important factors that contribute to the global warming. Otherwise HC result from the incomplete combustion of fuels. Their subsequent reactions with the sunlight causes smog and ground level Ozone formation. Volatile Organic Compound is a special group of Hydrocarbons which are divided into two types' methane (MTH) and non-methane (NMTH). It is seen that prolonged exposure to some of these compounds, such as Benzene Toluene and Xylene, to the sunlight can cause Leukaemia. ${ }^{2}$

The important impact on human health and environment has grown the interest to analyze the adverse effect of air pollution in Tirana district by measuring and estimating the level of $\mathrm{HC}$ emissions and $\mathrm{CO}_{2}$ during the last decade. We have selected for our analysis two different passenger cars type such as Lancia Thesis and Citroen C4, production years 2004 and 2009, with different speed regimes. We have selected these two types of diesel passenger cars for two reasons; firstly they are in the group that "Pass" successfully the official emission test in Tirana test center over the normal regime and secondly from diesel engine emissions were determined by the combustion process within the cylinder.

Emission standards for passenger cars are summarized in the Table $1 .^{3,8}$ Starting from the Euro 2 till Euro 6 stage, EU regulations introduce different emission limits for diesel. Diesels engines have more stringent CO standards but allowed higher NOx emissions. The formation of $\mathrm{CO}_{2}$ is directly proportional to the fuel consumption of the engine which means that for reduction of $\mathrm{CO}_{2}$ the fuel consumption needs to be reduced. Base on it, the target of EU for 2020 is to reduce the consumption of the diesel fuel in $3.6 \mathrm{l} / 100 \mathrm{~km}$.

To analyse the adverse effect of air pollution in Tirana district we need to measure and evaluate the level of $\mathrm{HC}$, $\mathrm{NOx}$ emissions and $\mathrm{CO}_{2}$ during the last decade. We have selected for our analysis two different passenger cars type such as Lancia and Citroen, production years 2004 and 2009, with different speed regimes. We have chosen these categories for their larger number of the diesel passenger cars that pass successfully the air pollution test in Tirana test centre over the normal regime. From the other side this is not a real way of measuring emissions because the results may differ from the actual on-road emissions and it eliminates several factors that influences in the emissions level e.g., traffic, road gradient, hard accelerations, use of air conditioning, weather conditions and drivers influence.

Table 1: Emission standards for passenger cars. ${ }^{8}$

\begin{tabular}{|c|c|c|c|c|c|c|c|c|}
\hline Tier & Date & $\mathrm{CO}$ & THC & NMHC & NOx & $\mathrm{HC}+\mathrm{NOx}$ & PM & $\mathbf{P}[\# / \mathrm{km}]$ \\
\hline \multicolumn{9}{|l|}{ Diesel } \\
\hline Euro 1† & Jul-92 & $2.72(3.16)$ & - & - & - & $0.97(1.13)$ & $0.14(0.18)$ & - \\
\hline Euro 2 & Jan-96 & 1 & - & - & - & 0.7 & 0.08 & - \\
\hline Euro 3 & Jan-OO & 0.64 & - & - & 0.5 & 0.56 & 0.05 & - \\
\hline Euro 4 & Jan-05 & 0.5 & - & - & 0.25 & 0.3 & 0.025 & - \\
\hline Euro 5a & Sep-09 & 0.5 & - & - & 0.18 & 0.23 & 0.005 & - \\
\hline Euro 5b & Sep-11 & 0.5 & - & - & 0.18 & 0.23 & 0.005 & $6 \times 10^{11}$ \\
\hline Euro 6 & Sep-14 & 0.5 & - & - & 0.08 & 0.17 & 0.005 & $6 \times 10^{11}$ \\
\hline
\end{tabular}

This paper will be focused in the quantity of the impact of various diesel passenger cars speed regime and driver related factors on vehicle fuel consumption and emissions. The analysis indicates that passenger cars fuel consumption and emission scale increase considerably as the number of cars stops especially at high model speed. The HC and NOx emission rates are highly sensitive to the level of acceleration when compared to automatic speed in the range of 0 to $160 \mathrm{~km} / \mathrm{h}$. Thus, the research 
work shows that the use of average speed we have only explanatory variable which is inadequate for estimating passenger cars fuel consumption and especially $\mathrm{HC}$ and NOx emissions. The combustion products were measured through E8500 gas analyzer device and the measurements were realized in the highway road between Tirana and Durres. $^{7}$

\section{METHODS}

An E8500 gas analyser device was employed to the diesel passenger cars to measure the emission level in Tirana District as can be seen in the Figure 2.

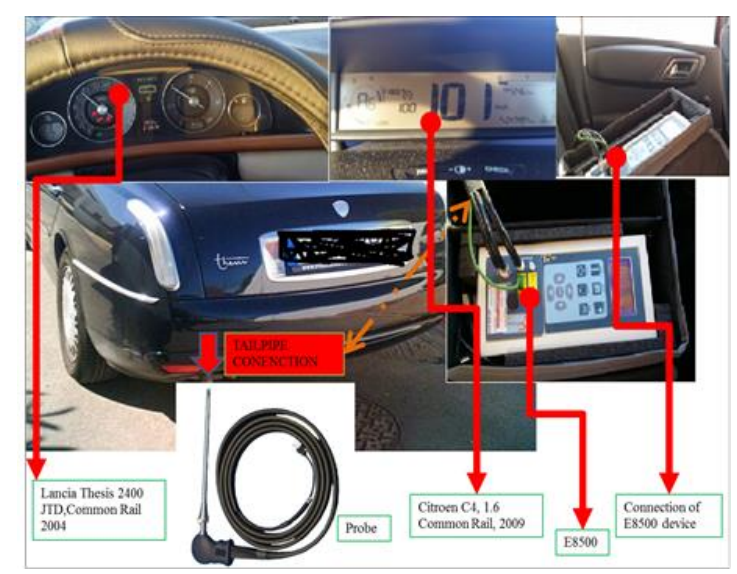

Figure 2: Connection of the E8500 Device with the Tailpipe exhaust system for the two types of the cars such as Lancia Thesis 2400 JTD, Common Rail, 2004 and Citroen C4 1.6, Common Rail, 2009.

From the Figure 2, the gas analyser device measures directly the gases that pass out through the tile pipe of the exhaust system of internal combustion engine. The E8500 is composed from nine total gas sensors, six electrochemical sensors, three high accuracy nondispersive infrared (NDIR) sensors and an optional photo ionization detection (PID) sensor for measuring the pollution components. E8500 gas analyzer play an important role to study the real emission of each diesel engines used in this study. This study analyzed the onroad emissions performance of diesel passenger cars by using portable emissions measurement system (PEMS), which provide a continuous stream of vehicle data signals including emission rates, velocity and exhaust temperature.

The measurement is realized for Lancia Thesis 2400 JTD (Common Rail) 2004 and Citroen C4 1.6, (Common Rail) 2009 in different speed regimes. Emissions were measured over urban zone and extra urbane highway Tirana-Durrës, in total more than 50 hours of operation and 500 kilometers driven. Furthermore, we have measured the emission of NOx for Citroen Xantia (Traditional diesel fuel pomp) 1998 and compare with the Citroen C4 1.6 (Common Rail) 2009. The following Table 2 shows the consumption data's per each of the two considers passenger cars given by manufacture fuel consumption.

Table 2: Manufacturer Fuel Consumption of Lancia Thesis 2400 JTD (Common Rail), 2004, and Citroen C4 1.6, (Common Rail), 2009.

\begin{tabular}{|lll|}
\hline $\begin{array}{l}\text { Fuel } \\
\text { Consumption }\end{array}$ & $\begin{array}{l}\text { Citroen C4 } \\
{[1 / \mathrm{km}]}\end{array}$ & $\begin{array}{l}\text { Lancia Thesis } \\
{[1 / \mathrm{km}]}\end{array}$ \\
\hline Urban & 6.0 & 9.8 \\
\hline Extra urban & 4.0 & 6.2 \\
\hline Combined & 4.7 & 7.5 \\
\hline
\end{tabular}

These manufacture fuel consumption values are not corresponding to the real fuel consumption values used in Tirana district because in most of the cases is dependent to the quality of the fuel. The $\mathrm{CO}_{2}$ emission $(E)$ in Tirana District for our diesel passenger's car has been expressed by equation 1 .

These manufacture fuel consumption values are not corresponding to the real fuel consumption values used in Tirana district because in most of the cases is dependent to the quality of the fuel. The $\mathrm{CO}_{2}$ emission $(E)$ in Tirana District for our diesel passenger's car has been expressed by equation 1 .

$$
E_{\mathrm{CO}_{2}}=\sum_{i=1}^{n} q \cdot A \cdot N_{i} \cdot b
$$

Where,

$q$ is the specific consumption per $100 \mathrm{~km}$,

$A$ is annual (km/year),

$N_{i}$ is the total number of the diesel passenger's car per each category,

$b$ is the amount of $\mathrm{CO}_{2}$

Furthermore, measured value of the NOx in different speed regimes (urban and interurban roads) have been converted in $\mathrm{g} / \mathrm{km}$ by using emission factor $(E F)$ of the equation 2 and 3.

$$
\begin{aligned}
& E F_{N O x}=\frac{p p m \cdot m_{g}}{10^{6}} \\
& E F_{H C}=\frac{p p m \cdot m_{g}}{10^{6}}
\end{aligned}
$$

Where, ppm is concentration of $\mathrm{HC}$ and $\mathrm{NOx}$, $m_{g}$ is a mass of the exhaust gas at $100^{\circ} \mathrm{C}$ measured from E8500. 


\section{RESULTS}

The summary results of the fuel consumption in relation of the speed regimes are shown in the Figure 3.

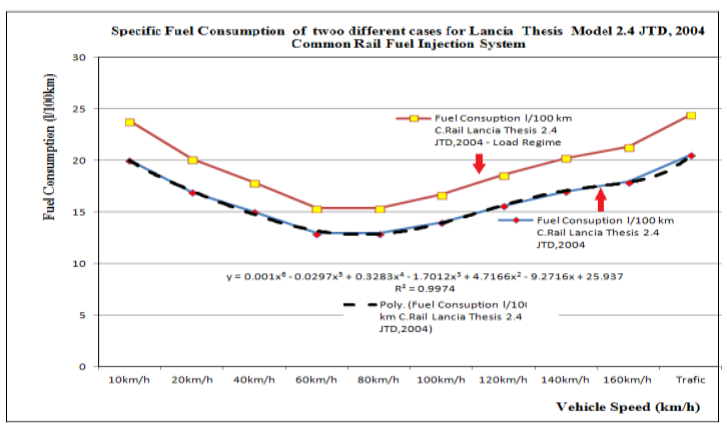

Figure 3 (a): Fuel consumption of Lancia Thesis 2.4JTD 2004 in load regime and normal operation regime.

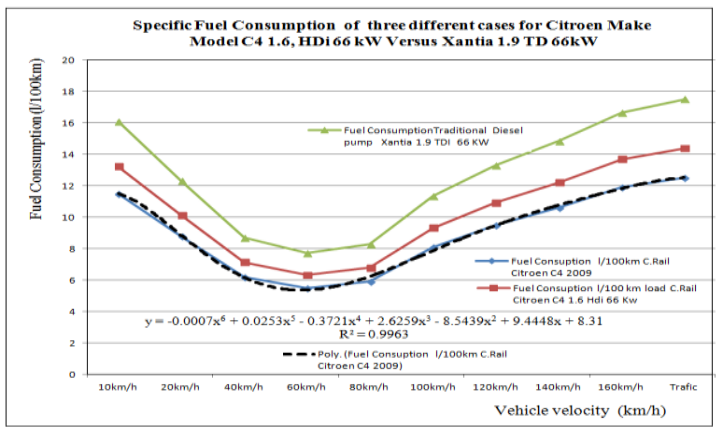

Figure 3 (b): Fuel consumption differences of Citroen (C4 \& Xantia) load regime and normal operation regime.

The above Figure 3 depicts the average speed of the driving style changes where the resulting fuel consumption follows the same U-shape observed for steady-speed driving. Each point in the figure represents the average velocity and fuel consumption for an entire speed trace. For each of the twelve speed traces, the minimum fuel consumption occurs at moderate speed. The speeds correspond $45-70 \mathrm{~km} / \mathrm{h}$ for Lancia Thesis, 45 $70 \mathrm{~km} / \mathrm{h}$ for Citroen C4 and Citroen Xantia. These are Optimal Speeds (OS) of the fuel consumption that correspond to the minimum emission values of $\mathrm{CO}_{2}$ as can be seen in the Figure 4. The values outside of the OS simultaneously increase/decrease the $\mathrm{CO}_{2}$ by increasing/decreasing the fuel consumption. Based on the fuel consumption, the emission of $\mathrm{CO}_{2}$ per each diesel passenger has been evaluated by equation 1 which correspond for $E_{\mathrm{CO} 2}$ (Lancia Thesis) $=636 \mathrm{~g} / \mathrm{km}, E_{\mathrm{CO} 2}$ $($ Citroen C4 $)=371 \mathrm{~g} / \mathrm{km}$ and $E_{\mathrm{CO} 2}($ Citroen Xantia $)=450$ $\mathrm{g} / \mathrm{km}$.

Figure 5, shows the content of the $\mathrm{HC}$ in relation of the speed regime for Lancia Thesis and Citroen $\mathrm{C} 4$ diesel passenger cars.

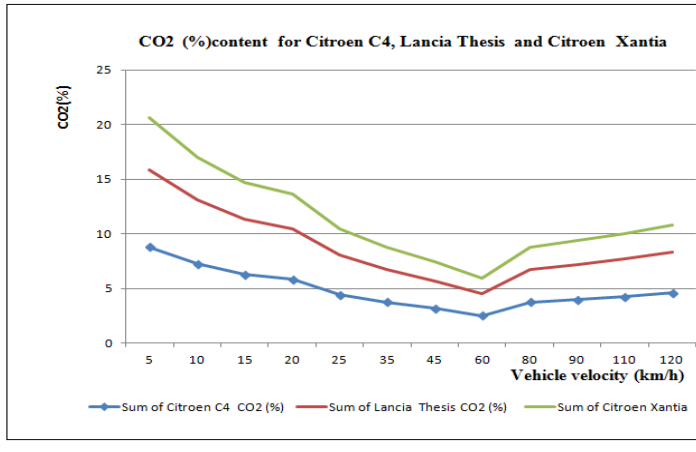

Figure 4: $\mathrm{CO}_{2}$ content for Lancia Thesis, Citroen $\mathrm{C4}$ and Citroen Xantia in different speed regimes.
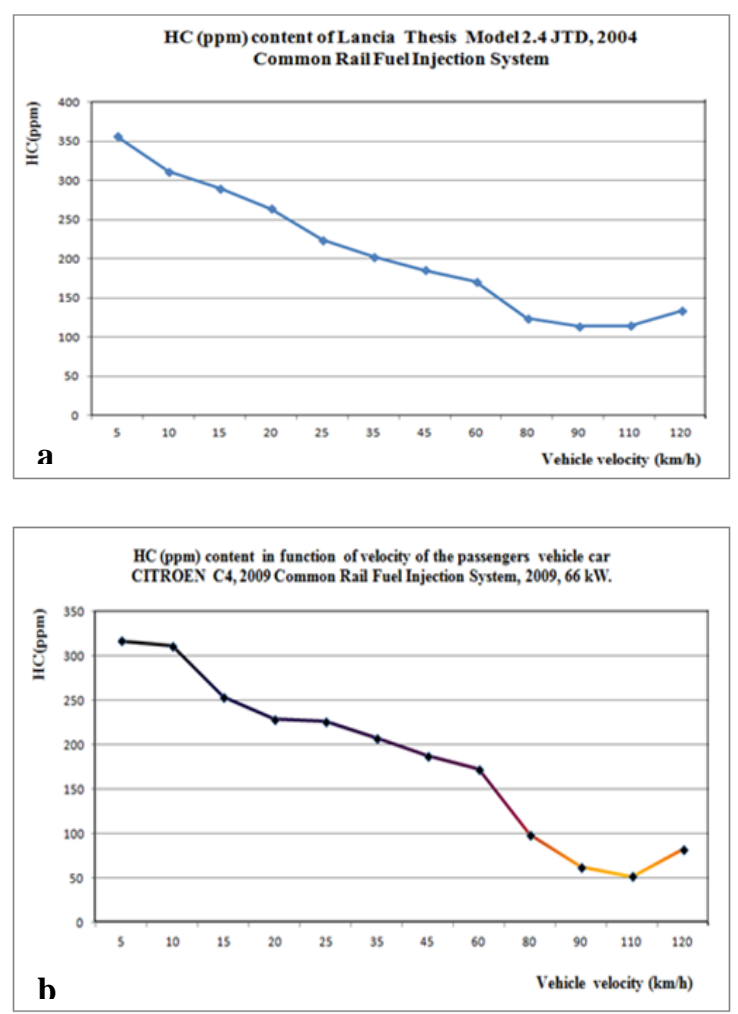

Figure 5: Content of $\mathrm{HC}$ in ppm for driving cycle Tirana-Durres highway: (a) Lancia Thesis and (b) Citroen C4.

The above Figure 5 depicts that the $\mathrm{HC}$ content is increased by increasing the speed regime. By using equation 3 we have evaluated the emissions of the $\mathrm{HC}$ which are for EFHC (Lancia Thesis) $=0.9 \mathrm{~g} / \mathrm{km}$ and EFHC $($ Citroen C4 $)=0.7 \mathrm{~g} / \mathrm{km}$.

The results of $\mathrm{HC}$ content in (ppm) versus Excess Air for different speed regimes is shown in the Figure 6.

Figure 7, shows the content of the NOx in relation of the speed regime for different diesel passenger cars. 

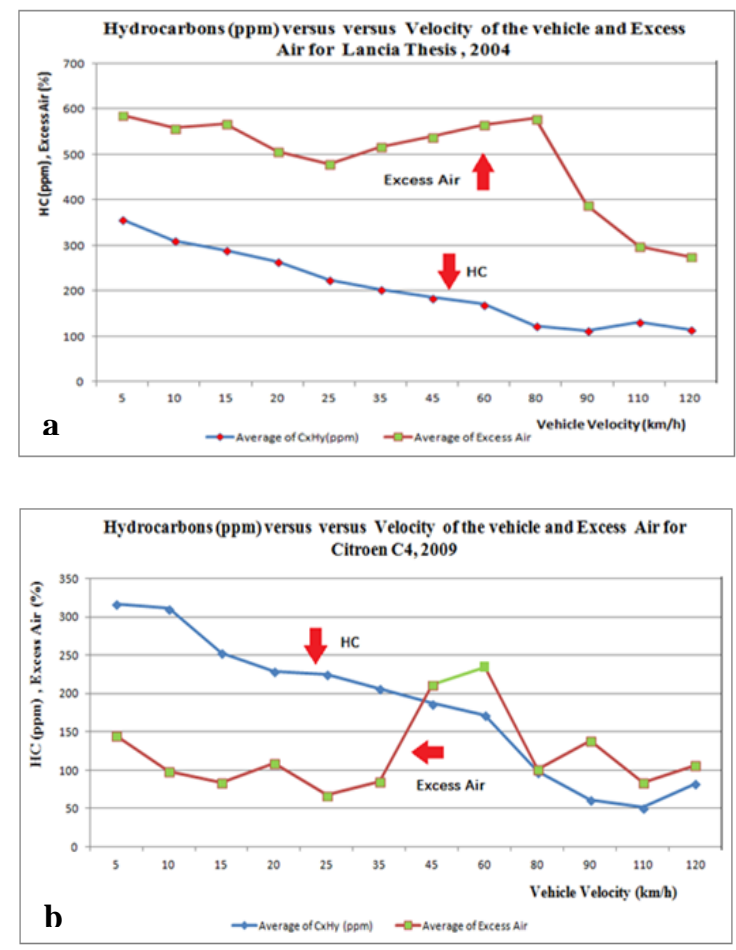

Figure 6: Content of $\mathrm{HC}$ in (ppm) versus Excess Air and vehicle speed profile of (a) Lancia Thesis and (b) Citroen C4 for driving cycle Tirana-Durres highway.
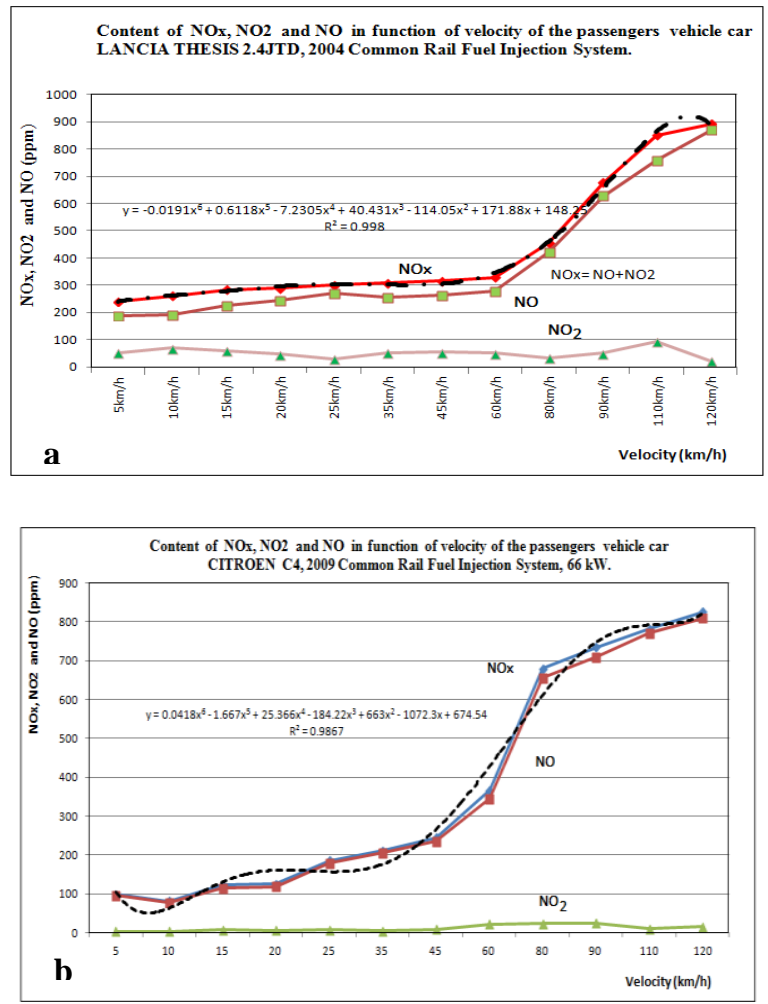

Figure 7: NOx profile content in (ppm) of (a) Lancia Thesis and (b) Citroen C4, for driving cycle TiranaDurres highway.
The above Figure 7 depicts that the NOx content is increased by increasing the speed regime. By using equation 2 and 3 we have evaluated the emission of the NOx which are for $E F_{\text {NOx }}$ (Lancia Thesis) $=1.62 \mathrm{~g} / \mathrm{km}$, $E F_{\mathrm{HC}}($ Lancia Thesis $)=0.9 \mathrm{~g} / \mathrm{km}, E F_{\text {NOx }}($ Citroen $\mathrm{C} 4)=$ $1.44 \mathrm{~g} / \mathrm{km}$ and $E F_{\mathrm{HC}}($ Citroen C4) $=0.7 \mathrm{~g} / \mathrm{km}$.

\section{DISCUSSION}

In this paper, the $\mathrm{HC}, \mathrm{NOx}$ and $\mathrm{CO}_{2}$ Emission level for Lancia Thesis, Citroen C4 and Citroen Xantia in Tirana district has been presented. The diesel passenger cars Lancia Thesis and Citroen $\mathrm{C} 4$ has been tested in PEMS method in different speed regimes and "Fail" in the emission test even they were new cars. It is seen that vehicle car with traditional diesel pump Citroen Xantia represent $38 \%$ more fuel consumption compared to the Common Rail fuel injection of Citroen C4, this mean low emission rate.

This study shows that the fuel consumption has U-shape form regarding to the velocity of the car, it is seen in Figure 6 for the three types of diesel passenger cars. The minimum fuel consumption occurs at moderate speed, between 45 and $70 \mathrm{~km} / \mathrm{h}$.

HC emission level for two diesel passenger cars, Citroen C4 and Lancia Thesis, were very high compared to EU 5 emission standard. On average, $\mathrm{HC}$ emissions from the tested vehicles were about 8 times higher than the limits set by the Euro 5. The highest level of $\mathrm{HC}$ was at speed level below $10 \mathrm{~km} / \mathrm{h}$ where this value correspond to 316 ppm and is 25 time higher than the limit set by Euro 5 . The lowest value corresponds in the vehicle speed 110 $\mathrm{km} / \mathrm{h}$ where $\mathrm{HC}$ value is $51.6 \mathrm{ppm}$ and is 4 times higher than EU standard.

In congestion condition in Tirana City the $\mathrm{HC}$ values of the two cars were different, for Lancia Thesis, which is classified as a luxury car reach 347 ppm otherwise for Citroen $\mathrm{C} 4$ a city car and small diesel passenger car $\mathrm{HC}$ content is $232 \mathrm{ppm}$, giving a value 1.5 times lower compared with Lancia Thesis.

Another important factor that has an influence in the $\mathrm{HC}$ pollution scale was excess air. The OS of this parameter plays an important role in reducing $\mathrm{HC}$. The excess air at Citroen $\mathrm{C} 4$ and Lancia Thesis grows the HC values. The OS and high temperature in the burning chamber is needed to reduce the $\mathrm{HC}$ values.

NOx emission level for two diesel passenger cars, Citroen C4 and Lancia Thesis, is very high compared to EU 5 emission standard. ${ }^{8}$ On average, real-world NOx emissions from the tested vehicles were about eighteen times higher than the limits set by the Euro 6 standard and 8 times higher than the limits set by the Euro 5 . 
Funding: No funding sources

Conflict of interest: None declared

Ethical approval: Not required

\section{REFERENCES}

1. Albanian Health Institute (ISHP). Albanian Health Institute Report Study, 2000-2010: Pollution from the Vehicles That Influence in Health Diseases. May 222010 http://ishp.gov.al. Accessed 15 Feb 2016.

2. World Health Organization August 2015. http://www.who.int/ipcs/features/benzene.pdf. Accessed 15 Feb 2016.

3. Malka L, Bidaj F. Opacity Evaluation for Passenger Diesel Vehicle Cars in Tirana. Journal of Environmental Science and Engineering. 2015;4(7):352-8.

4. Zhang Q, Streets GD, He K, Wang Y, Richter A, Burrows PJ, et al. NOx emission trends for China, 1995-2004: The view from the ground and the view from space. J Geophys Res Atmos. 2007;112(1):118 .
5. Zhao B, Wang XS, Liu H, Xu YJ, Fu K, Klimont Z, et al. NOx emissions in China: historical trends and future perspectives. J Atmos Chem Phys. 2013;13(1):9869-97.

6. Mueller FS, Bailey ME, Kelsoe J. Geographic sensitivity of fine particle mass to emissions of $\mathrm{SO}_{2}$ and NOx. Environ Sci Technol. 2004;38(1):570-80.

7. Manual of E8500 gas analyzer device. http://www.e-inst.com/industrial-gas-analyzers/ products-E8500. Accessed 15 Feb 2016.

8. European Standards for Passengers Vehicles, "Europeans Standards for Passengers Vehicles Strategic Plan, 2003-2013", July 29, 2013 https://www.dieselnet.com/standards/eu/ld.php. Accessed 15 Feb 2016.

Cite this article as: Malka L, Dhoska K. Analysis of environmental impact caused from diesel passenger cars in Tirana district by using PEMS method: cases of Lancia and Citroen. Int J Sci Rep 2016;2(6):110-5. 